\title{
Can base excess and anion gap predict lactate level in diagnosis of septic shock?
}

\author{
Werapon Pongmanee' \\ Veerapong Vattanavanit ${ }^{2}$ \\ 'Department of Internal Medicine, \\ ${ }^{2}$ Division of Critical Care Medicine, \\ Department of Internal Medicine, \\ Faculty of Medicine, Prince of Songkla \\ University, Hat Yai, Songkhla, Thailand
}

This article was published in the following Dove Press journal: Open Access Emergency Medicine

Background: Lactate measurement is the key component in septic shock identification and resuscitation. However, point-of-care lactate testing is not widely used due to the lack of access to nearby test equipment. Biomarkers such as serum lactate, anion gap (AG), and base excess (BE) are used in determining shock in patients with seemingly normal vital signs.

Purpose: We aimed to determine if these biomarkers can be used interchangeably in patients with septic shock in the emergency setting.

Patients and methods: A prospective observational cohort study was undertaken at a tertiary hospital in southern Thailand. Baseline point-of-care BE, AG, and serum lactate were recorded in all patients presenting with septic shock at the emergency department. Overall correlations including area under the receiver operating characteristic curve (AUROC) for both BE and AG to predict serum lactate level were calculated.

Results: One hundred and fifteen patients were enrolled. Pearson correlation of serum lactate to $\mathrm{BE}$ was $-0.59\left(r^{2}=0.35 ; 95 \%\right.$ confidence interval $[\mathrm{CI}],-0.69$ to $\left.-0.44 ; P<0.001\right)$ and $\mathrm{BE}$ to AG was $-0.67\left(r^{2}=0.49 ; 95 \% \mathrm{CI},-0.76\right.$ to $\left.-0.55 ; P<0.001\right)$, and serum lactate to AG was $0.64\left(r^{2}=0.41 ; 95 \%\right.$ CI, 0.52 to $\left.0.74 ; P<0.001\right)$. A cut-off point of 15.8 for AG identified a lactate level $\geq 2 \mathrm{mmol} / \mathrm{L}$ (sensitivity, $71.4 \%$; specificity, $80.7 \%$; and AUROC, 0.76 ), and the best cut-off value to predict a lactate level $\geq 4 \mathrm{mmol} / \mathrm{L}$ was 18.5 (sensitivity, $64.2 \%$; specificity, 85.5\%; and AUROC 0.78).

Conclusion: In patients with septic shock, lactate and AG showed a strong correlation with each other, whereas lactate and BE showed a moderate correlation with each other. Thus, these biomarkers can be used interchangeably to help determine septic shock earlier in patients.

Keywords: base excess, anion gap, lactate, septic shock

\section{Introduction}

Septic shock is a syndrome of pathologic, physiologic, and biochemical disturbances caused by infection, and it is a major public health concern worldwide. ${ }^{1,2}$ The overall mortality rate and cost of treatment are high. Many techniques have been developed for the early detection of septic shock and prompt resuscitation.

Lactate is a key component in the diagnosis of septic shock because it is released from tissue in the hypoperfusion state before hypotension. Lactate-guided resuscitation decreased mortality in patients with septic shock compared to that of resuscitation without lactate monitoring ${ }^{3}$ or central venous oxygen saturation-oriented therapy. ${ }^{4}$ In 2016, the international consensus launched a new sepsis definition (Sepsis-3), which is composed of the sepsis condition, the need for a vasopressor to maintain a mean

Correspondence: Veerapong Vattanavanit

Department of Internal Medicine, Faculty of Medicine, Prince of Songkla University, I5 Kanjanavanich Road, Hat Yai, Songkhla 90II0, Thailand

Tel +66848456228

Fax +6674429385

Email vveerapong@gmail.com 
arterial pressure of $\geq 65 \mathrm{mmHg}$ and a serum lactate level $\geq 2 \mathrm{mmol} / \mathrm{L}$ in the absence of hypovolemia. ${ }^{2}$

Besides the diagnosis, lactate is a biomarker of shock state, which indicates immediate fluid resuscitation. In the Surviving Sepsis Campaign 2012 and 2016, patients who have a serum lactate level $\geq 4 \mathrm{mmol} / \mathrm{L}$ are identified as needing fluid resuscitation. ${ }^{5,6}$ The resuscitation endpoint should be aimed at normalizing lactate.

However, point-of-care lactate measurement is not widely used due to the lack of access to close at hand investigation equipment especially in developing countries. ${ }^{7,8}$ Other biomarkers usually tested from arterial blood gas in critically ill patients are anion gap (AG) and base excess (BE), which seem to be promising alternatives. Some evidence showed that BE correlated with an elevated lactate level in patients with sepsis ${ }^{9}$ and could predict mortality in patients with traumatic shock. ${ }^{10}$ A study revealed similar test characteristics among $\mathrm{AG}, \mathrm{BE}$, and lactate in traumatic shock. ${ }^{11}$

The aims of the study were to determine if lactate, BE, and AG can be used interchangeably in patients with septic shock in the emergency setting based on the test characteristics and correlation with each other and to evaluate the best cut-off values of $\mathrm{AG}$ and $\mathrm{BE}$ to predict lactate levels of $\geq 2$ and $\geq 4 \mathrm{mmol} / \mathrm{L}$.

\section{Patients and methods Study design}

This prospective cohort observational study was conducted from April to December 2016 in the emergency department of Songklanagarind Hospital, which is an 800-bed tertiary hospital in southern Thailand. The inclusion criteria were patients older than 18 years and with septic shock according to the 2001 task force definition ${ }^{12}$ by emergency physicians. Septic shock was defined as a state of acute circulatory failure characterized by persistent arterial hypotension unexplained by other causes. Hypotension was defined as a systolic arterial pressure less than $90 \mathrm{mmHg}$, mean arterial pressure less than $60 \mathrm{mmHg}$, or a reduction in systolic blood pressure more than $40 \mathrm{mmHg}$ from baseline, despite adequate volume resuscitation, in the absence of other cause of hypotension. Patients were excluded if they were younger than 18 years or have incomplete data. Two sets of blood samples were collected not more than $30 \mathrm{~min}$ apart. In the first set, lactate and BE samples were obtained from arterial blood using a disposable syringe (NIPRO Corporation Limited, Phra Nakhon Si Ayutthaya, Thailand) and then processed with a blood gas analyzer (ABL800 FLEX). In the second set, venous blood was drawn to detect electrolytes (sodium, chloride, and bicarbonate) and albumin using a spray-dried lithium-coated tube (VACUETTE, BIP, Bangkok, Thailand), which was analyzed in the central laboratory auto-analyzer (Cobas ${ }^{\circledR} 8000$ modular analyzer, Roche Diagnostics, Indianapolis, IN, USA). The ethics committee of the Faculty of Medicine, Prince of Songkla University, waived the need for written informed consent as this was an observational study of data already collected during usual resuscitations. The protocol of this study was approved by the ethics committee of the Faculty of Medicine, Prince of Songkla University (EC number: 58-379-14-4).

\section{Data}

The baseline patient characteristics included age, sex, body weight, height, comorbidities, sources of infection, and conditions due to increased lactate level (ie, renal failure, liver failure, or medications). Data on hemodynamic parameters and other variables such as previous intravenous fluid, vasoactive agent, Sepsis-related Organ Failure Assessment (SOFA), hospital length of stay (LOS), days of mechanical ventilation, intensive care unit (ICU) LOS, ward LOS, in-hospital mortality, 28-day mortality, and the number of patients discharged home (Table 1) were obtained. Furthermore, other laboratory data were obtained, which included lactate level, BE, sodium $\left(\mathrm{Na}^{+}\right)$, chloride $\left(\mathrm{Cl}^{-}\right)$, bicarbonate $\left(\mathrm{HCO}_{3}^{-}\right)$, and albumin. $\mathrm{AG}$ was calculated from the $\mathrm{Na}^{+}-\mathrm{Cl}^{-}-\mathrm{HCO}_{3}^{-}$, and an albumincorrected $\mathrm{AG}$ was calculated from the following formula: albumin-corrected $\mathrm{AG}=(4-$ observed albumin $) \times 2.5+\mathrm{AG}$. $^{13}$

\section{Endpoints}

The primary objective of this study was to determine if correlations are present among the biomarkers of $\mathrm{AG}, \mathrm{BE}$, and lactate level in patients with septic shock. The secondary endpoint was to determine the test characteristics of AG and BE to predict a serum lactate level $\geq 2 \mathrm{mmol} / \mathrm{L}$ and a lactate level $\geq 4 \mathrm{mmol} / \mathrm{L}$.

\section{Statistical analysis}

Categorical data were presented as percentages. Continuous data were presented as mean $\pm \mathrm{SD}$ or median with minimum and maximum, interquartile range (IQR) depending on the distribution of the data. The data were tested for normality using the Kolmogorov-Smirnov goodness-of-fit test. Correlations of biomarkers were analyzed using the Pearson correlation. Test characteristics (sensitivity, specificity, positive predictive value, negative predictive value, and likelihood ratios) were analyzed using the receiver operating characteristic curve (ROC) to find the best cut-off points of 
$\mathrm{AG}$ and $\mathrm{BE}$ and predict a serum lactate level $\geq 2 \mathrm{mmol} / \mathrm{L}$ and lactate level $\geq 4 \mathrm{mmol} / \mathrm{L}$. The area under the receiver operating characteristic curve (AUROC) for each cut-off point was also calculated. All statistical analyses were performed with $\mathrm{R}$

Table I Baseline characteristics of septic shock patients $(n=115)$

\begin{tabular}{|c|c|}
\hline Variables & n (\%) \\
\hline Male & $70(6 \mathrm{I})$ \\
\hline Age (years), median (IQR) & $66(52-80)$ \\
\hline BW (kg), median (IQR) & $60(54-65)$ \\
\hline Height (cm), median (IQR) & $166(164.5-169)$ \\
\hline \multicolumn{2}{|l|}{ Comorbidities } \\
\hline Hypertension & $46(40)$ \\
\hline Malignancy & $24(20.9)$ \\
\hline Diabetes mellitus & $23(20)$ \\
\hline Ischemic heart disease & $23(20)$ \\
\hline CKD & $22(19.1)$ \\
\hline Cerebrovascular disease & $7(6.1)$ \\
\hline Liver disease & $5(4.3)$ \\
\hline Connective tissue disease & $4(3.5)$ \\
\hline HIVIAIDs & $3(2.6)$ \\
\hline Respiratory disease & $3(2.6)$ \\
\hline Others & $3(2.6)$ \\
\hline \multicolumn{2}{|l|}{ Source of infection } \\
\hline Respiratory disease & $40(34.8)$ \\
\hline Urinary tract & $20(17.4)$ \\
\hline Gastrointestinal tract & $18(15.7)$ \\
\hline Skin and soft tissue & $9(7.8)$ \\
\hline Hepatobiliary tract & $6(5.2)$ \\
\hline Others & $86(74.8)$ \\
\hline Positive blood cultures & $32(27.8)$ \\
\hline \multicolumn{2}{|l|}{ Organisms identified in blood cultures } \\
\hline Escherichia coli & $15(46.8)$ \\
\hline Staphylococcus aureus & $4(12.5)$ \\
\hline Acinetobacter baumannii & $3(9.3)$ \\
\hline Others & $10(31.2)$ \\
\hline \multicolumn{2}{|l|}{ Hemodynamics during diagnosis septic shock } \\
\hline $\operatorname{MAP}(\mathrm{mmHg})$, median $(\mathrm{IQR})$ & $69(62-70)$ \\
\hline HR (bpm), median (IQR) & $112(103-122)$ \\
\hline RR (bpm), median (IQR) & $22(22-28)$ \\
\hline Previous IV fluid (mL), median (IQR) & $2,000(2,000-3,000)$ \\
\hline Patients received vasoactive agent $(s)^{\mathrm{a}}$ & $115(100)$ \\
\hline Norepinephrine dose $(\mathrm{mg} / \mathrm{kg} / \mathrm{min})$, median (IQR) & $0.2(0.1-0.2)$ \\
\hline SOFA, median (IQR) & $9(8-11)$ \\
\hline LOS (days), median (IQR) & $15(8-24)$ \\
\hline Mechanical ventilation (days), median (IQR) & $4(2-8)$ \\
\hline ICU LOS (day), median (IQR) & $5(2-10)$ \\
\hline Ward LOS(day), median (IQR) & $10(3-17.5)$ \\
\hline In-hospital mortality & $51(44.3)$ \\
\hline 28-day mortality & $44(38.3)$ \\
\hline Discharged home & $60(52.2)$ \\
\hline
\end{tabular}

Notes: Data are presented as $n(\%)$ unless indicated otherwise. ${ }^{a} \mathrm{All}$ patients received norepinephrine and one patient received both norepinephrine and dopamine. Abbreviations: IQR, interquartile range; BW, body weight; CKD, chronic kidney disease; HIVIAIDS, human immunodeficiency virus/acquired immunodeficiency syndrome; MAP, mean arterial pressure; HR, heart rate; RR, respiratory rate; IV, intravenous; ICU, intensive care unit; LOS, length of stay; SOFA, Sepsis-related Organ Failure Assessment. software version 3.3.1 (R Foundation for Statistical Computing, Vienna, Austria).

\section{Results Sample and measures}

We enrolled a total of 115 patients with septic shock. The median age was 66 years (IQR, 52-80 years), and 61\% were men. About $35 \%$ of the septic shock patients had pneumonia. The median SOFA score was 9 (IQR, 8-11). In-hospital mortality was about $44 \%$ and 28 -day mortality was about $38 \%$. Approximately half of the septic patients were discharged home (Table 1). The median lactate level was $3.5 \mathrm{mmol} / \mathrm{L}$ (IQR, 1.7-6.2), the mean serum BE was -8.3 (SD \pm 6.7 ), and the median AG was 16.7 (IQR, 14.2-22.1; Table 2).

\section{Endpoints}

The results for the primary endpoints showed a strong correlation between the AG and lactate and a moderate correlation between the BE and lactate. The Pearson correlation of serum lactate to $\mathrm{BE}$ was $-0.59\left(r^{2}=0.35 ; 95 \%\right.$ confidence interval [CI], -0.69 to $-0.44 ; P<0.001), \mathrm{BE}$ to $\mathrm{AG}$ was $-0.67\left(r^{2}=\right.$ $0.49 ; 95 \% \mathrm{CI},-0.76$ to $-0.55 ; P<0.001)$, and the correlation of serum lactate to AG was $0.64\left(r^{2}=0.41 ; 95 \% \mathrm{CI}, 0.52\right.$ to $0.74 ; P<0.001)$. In addition, the corrected AG showed a seemingly good correlation with lactate that was the same with the correlation between the AG and lactate, which was $0.64\left(r^{2}=0.41 ; 95 \%\right.$ CI, 0.52 to $0.74 ; P<0.001$; Figure 1$)$. The results for the secondary endpoints showed a cut-off point of 15.8 for $\mathrm{AG}$, which identified a lactate level $\geq 2 \mathrm{mmol} / \mathrm{L}$ (sensitivity, 71.4\%; specificity, 80.7\%; AUROC, 0.76), and the best cut-off value to predict a lactate level $\geq 4 \mathrm{mmol} / \mathrm{L}$ was 18.5 (sensitivity, 64.2\%; specificity, 85.5\%; AUROC, 0.78 ; Figure 2).

Table 2 Biomarkers

\begin{tabular}{ll}
\hline Parameters & Mean (SD) \\
\hline Lactate level (mmol/L), median (IQR) & $3.5(1.7-6.2)$ \\
SBE & $-8.3(6.7)$ \\
Sodium level (mEq/L) & $137.2(6.6)$ \\
Chloride level (mEq/L) & $99.9(7.8)$ \\
Bicarbonate level (mEq/L) & $18.7(5.6)$ \\
Albumin (g/dL) (mEq/L) & $2.7(0.7)$ \\
AG, median (IQR) & $16.7(14.2-22.1)$ \\
Albumin-corrected AGb, median (IQR) & $17.2(14.7-22.3)$ \\
Positive urine ketones ${ }^{c}, \mathrm{n}(\%)$ & $10(8.7)$ \\
\hline
\end{tabular}

Notes: Data are presented as mean (SD) unless indicated otherwise. ${ }^{a} A G$ values were calculated by $\left(\mathrm{Na}^{+}-\mathrm{Cl}^{-}-\mathrm{HCO}_{3}^{-}\right)$. ${ }^{\text {b}} \mathrm{Albumin}$-corrected $\mathrm{AG}$ values were calculated by $([4-$ albumin $] \times 2.5+A G)$. CUrine ketones were measured in 83 patients. Only two patients had serum ketones measured, and the results were positive.

Abbreviations: $A G$, anion gap; IQR, interquartile range; SBE, standard base excess. 
A

Correlation of BE to serum lactate

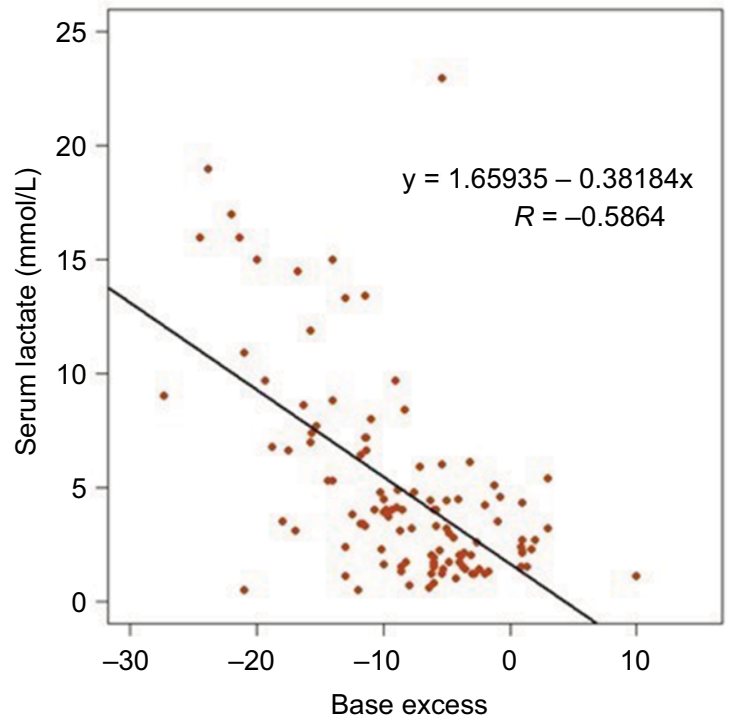

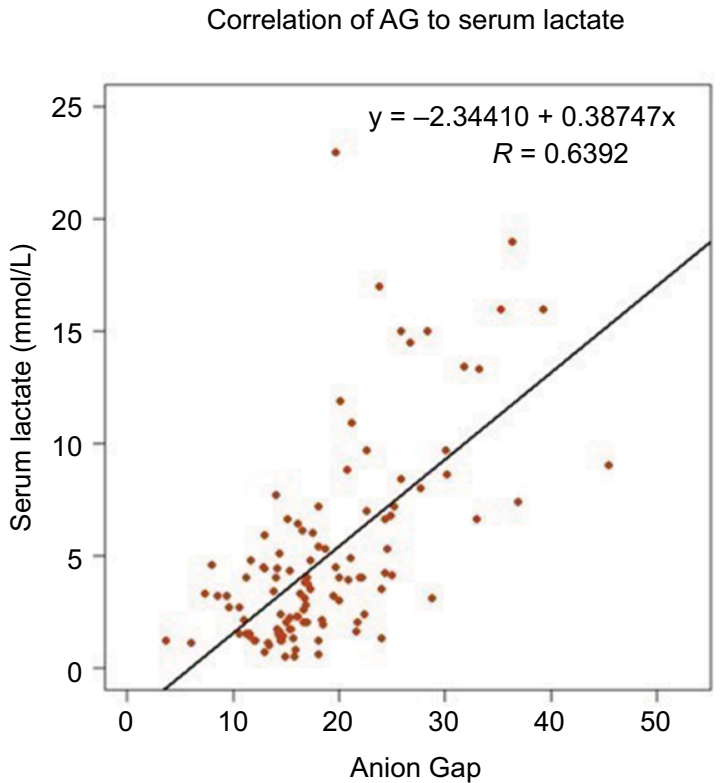

C

Correlation of albumin-corrected AG to

serum lactate

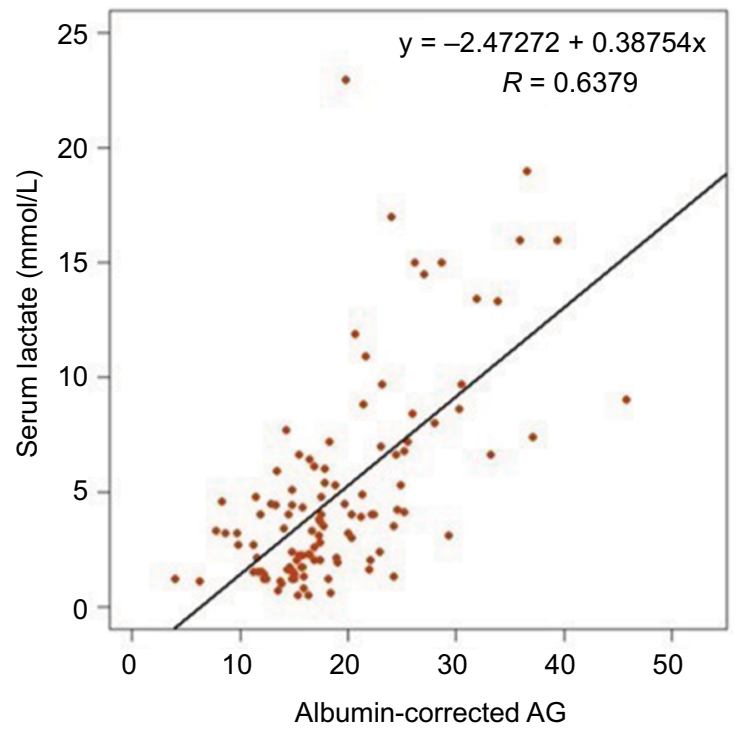

Figure I (A-C) Correlation of serum lactate to BE, AG, and corrected AG.

Abbreviations: $A G$, anion gap; $B E$, base excess.

\section{Discussion}

Our data indicated strong correlations across biomarkers in patients with septic shock in the emergency department. The $\mathrm{AG}$ and lactate showed a strong correlation with each other, whereas the $\mathrm{BE}$ and lactate showed a moderate correlation.

In patients with sepsis and septic shock, high AG metabolic acidosis is the dominant pattern of arterial blood gas. ${ }^{14}$ A previous study showed that an elevated AG had moderate sensitivity and specificity to detect elevated lactate in emergency patients at risk for sepsis. ${ }^{15}$ However, some studies reported that $\mathrm{AG}$ was insensitive for the presence of lactic acidosis in the emergency department setting. ${ }^{16,17}$

$\mathrm{BE}$ is defined as the amount of strong acid that must be added to each liter of fully oxygenated blood to return the $\mathrm{pH}$ to 7.40 at a temperature of $37^{\circ} \mathrm{C}$ and a $\mathrm{pCO}_{2}$ of $40 \mathrm{mmHg}$ $(5.3 \mathrm{kPa}) .^{18}$ 
A

ROC curve for $A G$ to predict lactate $\geq 2 \mathrm{mmol} / \mathrm{L}$

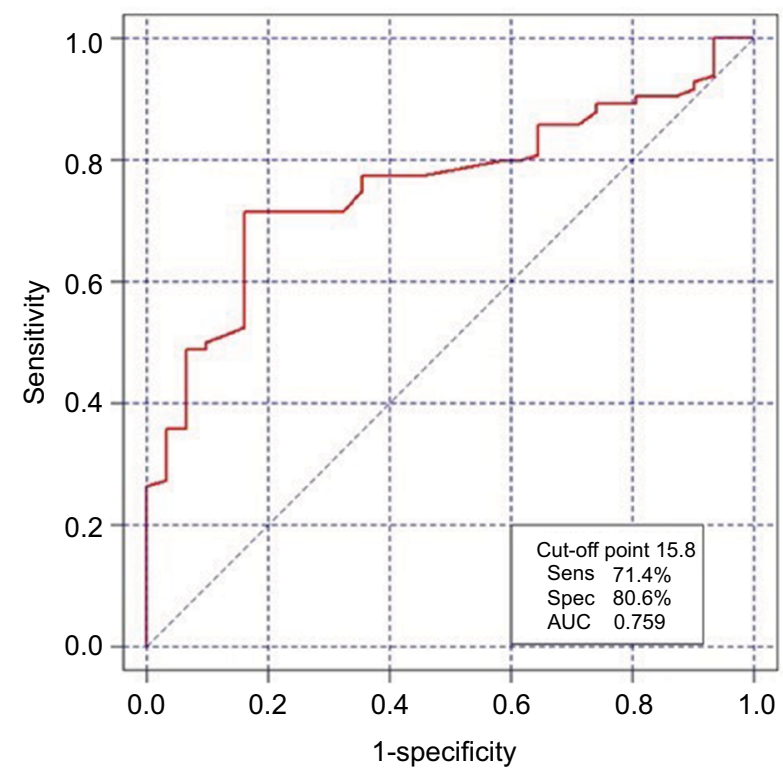

C

ROC curve for $A G$ to predict lactate $\geq 4 \mathrm{mmol} / \mathrm{L}$

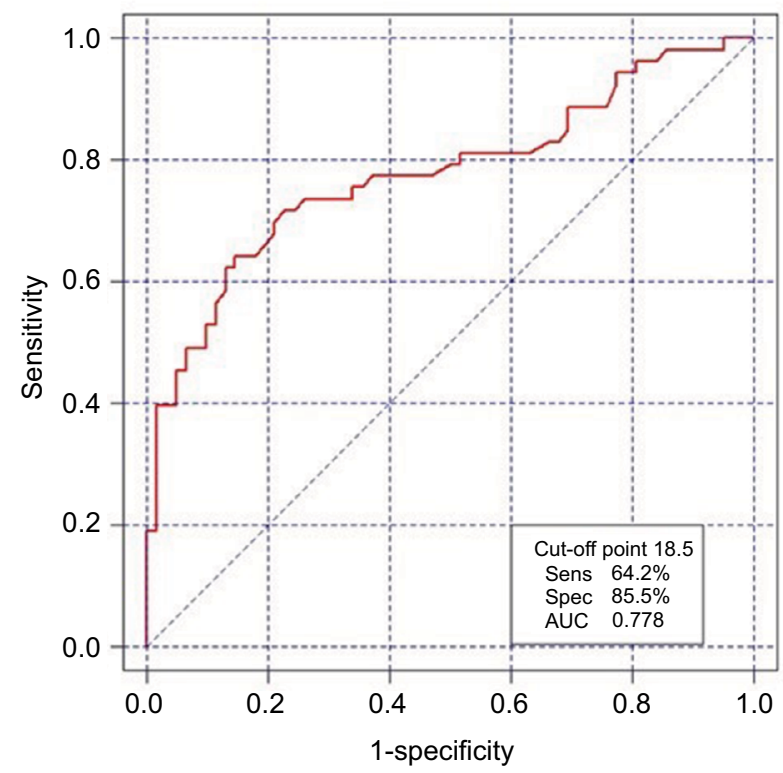

B

ROC curve for BE to predict lactate $\geq 2 \mathrm{mmol} / \mathrm{L}$

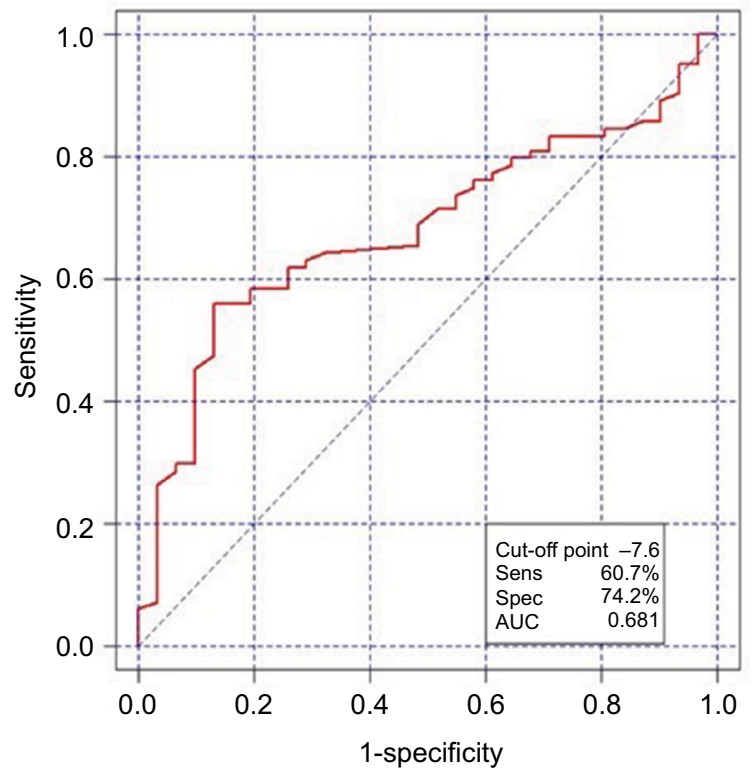

D

ROC curve for $B E$ to predict lactate $\geq 4 \mathrm{mmol} / \mathrm{L}$

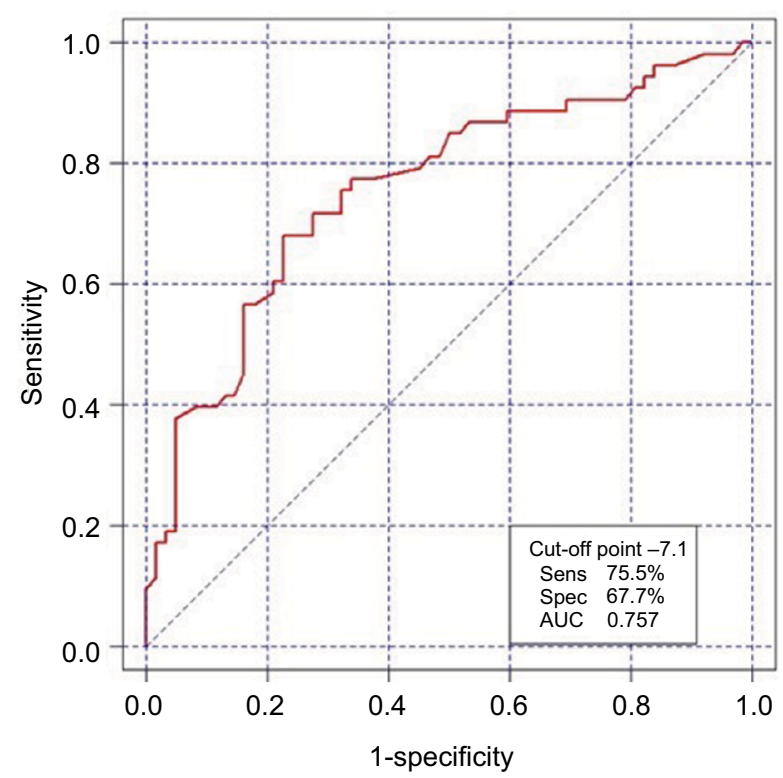

Figure 2 (A-D) ROC curves of $A G$ and $B E$ for prediction of lactate level $\geq 2$ and $\geq 4 \mathrm{mmol} / \mathrm{L}$.

Abbreviations: AG, anion gap; AUC, area under the curve; BE, base excess; ROC, receiver operating characteristic; Sens, sensitivity; Spec, specificity.

In the previous study, evidence indicated that either BE or lactate, or a combination of the 2 , may be used to predict the outcome in ICU-admitted patients. ${ }^{19}$ Montassier et al reported that a $\mathrm{BE}$ less than $-4 \mathrm{mmol} / \mathrm{L}$ predicted a lactate level greater than $3 \mathrm{mmol} / \mathrm{L}$ with good sensitivity and specificity. In our study, we found that the $\mathrm{AG}$ and lactate showed a strong correlation with each other, whereas the $\mathrm{BE}$ and lactate showed a moderate correlation. One possible explanation is that in critically ill septic patients, there are many acid components (eg, lactic acidosis, ketoacidosis, and uremia) in which lactic acidosis was the primary component. Thus, a high AG reflected well with elevated lactate level. Another explanation is that the AG was calculated using direct measurement parameters from the central laboratory auto-analyzer, which were accurate. On the other hand, BE was calculated using parameters that were dependent on many 
variables in the arterial blood gas results. In addition, there is not much evidence on the correlation of BE with lactate level in patients with sepsis, and the evidence was found mostly in traumatic shock patients.

The best cut-off values for the AG were 15.8 and 18.5, which identified lactate levels of $\geq 2$ and $\geq 4 \mathrm{mmol} / \mathrm{L}$, respectively. This is the first study in the new Sepsis-3 definition era using the lactate level in correlation with clinical data in the diagnosis of sepsis. A previous study reported that an AG more than 12 predicted the lactate level greater than $4 \mathrm{mmol} / \mathrm{L},{ }^{15}$ but this level had poor prediction in another study. ${ }^{20}$ The population and blood gas analyzer tools should be a concern when a comparison is made between studies.

Traditionally, arterial blood lactate level is used as the standard method for lactate measurement. Venous lactate is highly correlated with arterial lactate, ${ }^{21,22}$ but the agreement was poor when lactate levels were higher than $4 \mathrm{mmol} / \mathrm{L}^{22}$ Theerawit et $\mathrm{al}^{22}$ suggested not to use the venous value as a substitute for the arterial measurement in sepsis regarding the absolute value. The point-of-care lactate measurement has good accuracy in patients with sepsis ${ }^{23}$ and has been recommended in resource poor settings. ${ }^{24}$ However, it is not widely used in many developing countries.

Zampieri et $\mathrm{al}^{25}$ reported on the associations between acid-base variables, specifically strong ion gap (SIG) with immunological activation. On the contrary, Ho et $\mathrm{al}^{26}$ showed in more than 6,800 patients that SIG was of modest prognostic significance in the critically ill, whereas lactate concentration was most important when comparing SIG with other acidbase markers. However, SIG is composed of many cations and anions that are not routinely checked in the initial blood sample, especially in rural areas.

We found that some patients $(31 / 115,27 \%)$ developed septic shock despite lactate levels less than $2 \mathrm{mmol} / \mathrm{L}$. According to the Vasopressin in Septic Shock Trial, some patients with sepsis had a normal lactate range. ${ }^{27}$ The results showed that patients who had a lactate level in the normal range (ie, 1.4-2.3 $\mathrm{mmol} / \mathrm{L}$ ) had significantly increased mortality and organ dysfunction compared with patients who had a lactate level $\leq 1.4 \mathrm{mmol} / \mathrm{L}$. Furthermore, mortality was not different between patients with serum lactate levels of $1.4-2.3 \mathrm{mmol} / \mathrm{L}$ and $2.3-4.4 \mathrm{mmol} / \mathrm{L}$. The possibility of a normal lactate in a patient with sepsis may be explained by a less severe disease that had minimal or no end-organ failure.

The strength of this study is the use of many biomarkers to predict the lactate level in patients with septic shock. The results can be applied in developing countries and remote hospitals that lack instruments for point-of-care lactate measurement. However, sepsis is a dynamic process where clinicians should incorporate clinical data with laboratory data. Only a single AG or BE measurement may interfere with therapeutic interventions that can affect the patients' conditions and underlying diseases. ${ }^{28}$

This study has several limitations. First, the sample size in our study was limited due to the single-center observational study design. Second, we did not clearly identify underlying diseases that could cause a high AG and elevated lactate levels such as renal failure, intoxication, and ketoacidosis. Furthermore, a sensitivity analysis of all confounders that could cause an elevated lactate level was not performed. Third, the arterial blood gas analyzers may be different in other institutions. However, the variation was assumed to be low according to the machine calibration. ${ }^{29}$ Fourth, we did not design the study to find any association of these biomarkers other than lactate that correlated with mortality. In addition, we found that $\mathrm{AG}$ had a greater turnaround time compared with BE due to the availability of the measurement machine.

\section{Conclusion}

In conclusion, we demonstrated that in patients with septic shock, lactate and AG showed a strong correlation with each other, whereas lactate and BE showed a moderate correlation with each other. Thus, these biomarkers can be used interchangeably to help in the early determination of septic shock, and the physician should be on high alert for evaluation in septic patients with a high AG. The results showed that cut-off points of $\mathrm{AG}$ of 15.8 and 18.5 can be used to predict a serum lactate level greater than 2 and $4 \mathrm{mmol} / \mathrm{L}$, respectively.

\section{Acknowledgments}

The authors are grateful to the International Affairs Department, Faculty of Medicine, Prince of Songkla University for the language correction services. This study was supported by a research grant of the Faculty of Medicine, Prince of Songkla University. The abstract of this article was presented at the Sepsis 2017, Paris, France, September 11-13, 2017 as a poster presentation with interim findings. The poster's abstract was published in "Poster Abstracts" in Intensive Care Medicine Experimental 2017;5(Suppl 1):37; doi: 10.1186/ s40635-017-0149-y.

\section{Author contributions}

All authors contributed toward data analysis, drafting and revisiting the paper and agree to be accountable for all aspects of the work. 


\section{Disclosure}

The authors report no conflicts of interest in this work.

\section{References}

1. Angus DC, van der Poll T. Severe sepsis and septic shock. $N$ Engl J Med. 2013;369(9):840-851.

2. Singer M, Deutschman CS, Seymour CW, et al. The third international consensus definitions for sepsis and septic shock (sepsis-3). JAMA. 2016;315(8):801-810.

3. Jansen TC, van Bommel J, Schoonderbeek FJ, et al; LACTATE Study Group. Early lactate-guided therapy in intensive care unit patients: a multicenter, open-label, randomized controlled trial. Am J Respir Crit Care Med. 2010;182(6):752-761.

4. Zhou X, Liu D, Su L, et al. Use of stepwise lactate kinetics-oriented hemodynamic therapy could improve the clinical outcomes of patients with sepsis-associated hyperlactatemia. Crit Care. 2017;21(1):33.

5. Dellinger RP, Levy MM, Rhodes A, et al; Surviving Sepsis Campaign Guidelines Committee Including the Pediatric Subgroup. Surviving sepsis campaign: international guidelines for management of severe sepsis and septic shock, 2012. Intensive Care Med. 2013;39(2): 165-228.

6. Dellinger RP, Schorr CA, Levy MM. A users' guide to the 2016 surviving sepsis guidelines. Intensive Care Med. 2017;43(3):299-303.

7. Kang MJ, Shin TG, Jo IJ, et al. Factors influencing compliance with early resuscitation bundle in the management of severe sepsis and septic shock. Shock. 2012;38(5):474-479.

8. Chittawatanarat K, Patjanasoontorn B, Rungruanghiranya S. Thai-shock survey 2013: survey of shock management in Thailand. J Med Assoc Thai. 2014;97(suppl 1):S108-S118.

9. Montassier E, Batard E, Segard J, et al. Base excess is an accurate predictor of elevated lactate in ED septic patients. Am J Emerg Med. 2012;30(1):184-187.

10. Ibrahim I, Chor WP, Chue KM, et al. Is arterial base deficit still a useful prognostic marker in trauma? A systematic review. Am J Emerg Med. 2016;34(3):626-635.

11. Caputo ND, Kanter M, Fraser R, Simon R. Comparing biomarkers of traumatic shock: the utility of anion gap, base excess, and serum lactate in the ED. Am J Emerg Med. 2015;33(9):1134-1139.

12. Levy MM, Fink MP, Marshall JC, et al; International Sepsis Definitions Conference. 2001 SCCM/ESICM/ACCP/ATS/SIS international sepsis definitions conference. Intensive Care Med. 2003;29(4):530-538.

13. Kraut JA, Nagami GT. The serum anion gap in the evaluation of acidbase disorders: what are its limitations and can its effectiveness be improved? Clin J Am Soc Nephrol. 2013;8(11):2018-2024.
14. Ganesh K, Sharma RN, Varghese J, Pillai MG. A profile of metabolic acidosis in patients with sepsis in an intensive care unit setting. Int $J$ Crit Illn Inj Sci. 2016;6(4):178-181.

15. Berkman M, Ufberg J, Nathanson LA, Shapiro NI. Anion gap as a screening tool for elevated lactate in patients with an increased risk of developing sepsis in the Emergency Department. J Emerg Med. 2009;36(4):391-394.

16. Aronovich D, Trotter M, Rivera C, et al. Is serum lactate necessary in patients with normal anion gap and serum bicarbonate? West J Emerg Med. 2015;16(3):364-366.

17. Xu Q, HowlettClyne S, Fuezery A, Cembrowski GS. Low sensitivity of anion gap to detect clinically significant lactic acidosis in the emergency department. Clin Biochem. 2017;50(18):1164-1167.

18. Kibble JD, Halsey CR. Renal physiology and acid-base balance. Medical physiology: the big picture. New York: McGraw-Hill Education; 2015.

19. Smith I, Kumar P, Molloy S, et al. Base excess and lactate as prognostic indicators for patients admitted to intensive care. Intensive Care Med. 2001;27(1):74-83.

20. Adams BD, Bonzani TA, Hunter CJ. The anion gap does not accurately screen for lactic acidosis in emergency department patients. Emerg MedJ. 2006;23(3):179-182.

21. Mikami A, Ohde S, Deshpande GA, Mochizuki T, Otani N, Ishimatsu S. Can we predict arterial lactate from venous lactate in the ED? Am J Emerg Med. 2013;31(7):1118-1120.

22. Theerawit P, Na Petvicharn C, Tangsujaritvijit V, Sutherasan Y. The correlation between arterial lactate and venous lactate in patients with sepsis and septic shock. J Intensive Care Med. Epub 2016 Aug 8.

23. Ismail F, Mackay WG, Kerry A, Staines H, Rooney KD. The accuracy and timeliness of a point of care lactate measurement in patients with sepsis. Scand J Trauma Resusc Emerg Med. 2015;23:68.

24. Khan M, Brown N, Mian AI. Point-of-care lactate measurement in resource-poor settings. Arch Dis Child. 2016;101(4):297-298.

25. Zampieri FG, Kellum JA, Park M, et al. Relationship between acid-base status and inflammation in the critically ill. Crit Care. 2014;18(4):R154.

26. Ho KM, Lan NS, Williams TA, et al. A comparison of prognostic significance of strong ion gap (SIG) with other acid-base markers in the critically ill: a cohort study. J Intensive Care. 2016;4:43.

27. Wacharasint P, Nakada TA, Boyd JH, Russell JA, Walley KR. Normalrange blood lactate concentration in septic shock is prognostic and predictive. Shock. 2012;38(1):4-10.

28. Glasmacher SA, Stones W. Anion gap as a prognostic tool for risk stratification in critically ill patients - a systematic review and metaanalysis. BMC Anesthesiol. 2016;16(1):68.

29. RADIOMETER. ABL800 FLEX Analyzer Specifications. Available from: http:/www.newtechnologyba.com/media/abl800flexspecifications.pdf. Accessed June 28, 2017.
Open Access Emergency Medicine

\section{Publish your work in this journal}

The Open Access Emergency Medicine is an international, peerreviewed, open access journal publishing original research, reports, editorials, reviews and commentaries on all aspects of emergency medicine. The manuscript management system is completely online and includes a very quick and fair peer-review system, which is all

\section{Dovepress}

easy to use. Visit http://www.dovepress.com/testimonials.php to read real quotes from published authors. 